\title{
Implementation of total productive maintenance (TPM) to increase overall equipment efficiency of an hotel industry
}

\author{
Manjunatha B..$^{*}$, Srinivas T. R. ${ }^{1}$ and Ramachandra C. G. ${ }^{2}$ \\ ${ }^{1}$ Department of Industrial and Production Engineering, Sri Jayachamarajendra College of \\ Engineering Mysuru, India \\ ${ }^{2}$ Department of Mechanical Engineering, Srinivas Institute of Technology, Mangaluru, India
}

\begin{abstract}
Hotel industries are one of the fastest growing areas in India, which is attracting more number of jobs \& tourists. This also results in direct impact on Indian economy. All Hotels comprises a higher element of total working cost and they are a good source of income. Hospitality is one of the most important components of hotel industry. To give a good hospitality in hotels to customers, we need to use different machines in different departments. For example if we take section of housekeeping it consists of different sub departments like Rooms \& corridors, Toilets, Linen, Furniture and furnishings, Gardens, Public areas etc. In this connection a small implementation of TPM tool called focused improvement \& planned maintenance, implemented in alternative usage of electrical systems (energy conservation). Result showed a very significant improvement in energy saving. By adopting Small changes show a significant improvement in the overall system. It also indicates the dire need of proper industrial tools in hotels. Total Productive Maintenance (TPM) is one of the pioneering approaches which can be achieved in above said things [1][2].
\end{abstract}

Keywords: Overall Equipment Efficiency (OEE), Total Productive Maintenance (TPM), Hotel Industries, Maintenance, Focused improvement, Planned Maintenance (PM).

\section{Introduction}

It is well known fact that in industrial situation huge losses/wastage occur in the manufacturing shop floor. It happens due to operators, maintenance personal, process, tooling problems and non-availability of components in time and many more. Indirect or hidden waste includes idle machines; idle manpower, machine break down, rejected parts etc. are all examples of waste [3]. Quality is very significant factor as they matter the company in terms of time, material and the hard earned reputation of the company. In recent trends companies are leaning towards Zero tolerance for waste, defects, break down $\&$ zero accidents in all departments. In order to overcome these problems, a innovative concept such as TPM has been successfully implemented in many industries across the globe to address the above said problems.

${ }^{*}$ Corresponding author: manjurmech@gmail.com 
Total Productive Maintenance (TPM) is a maintenance tool which enables to maintain the plants and equipments [4][5]. The goal of the TPM program is a well defined technique which increases production, efficiency, at the same time, increasing employee morale $\&$ job satisfaction.

General classifications of Machines and Equipments in Hotels:

$>$ Air conditioner machines

- VRF Centralized AC

- Split AC

- Cassette AC

$>$ Kitchen

- Fresh air supplier

- Exhaust

- Fresh air supplier

- Gasoline supplier

- Cold room

$>$ Water heater and laundry

- Electrical boilers and solar water heaters

House keeping

- Floors scrubbing machines

- Vacuum cleaner

$>$ Maintenance

- 125 D5 kVA Transformer

- $325 \mathrm{kVA}$ Transformer

- 800 kVA Transformer

\section{OEE (Overall Equipment Efficiency)}

The main objective of Total Productive Maintenance is to enhance the Overall Equipment Effectiveness of plant equipment.

OEE consists of three basic indicators of equipment performance and reliability. The three main factors of OEE is explained below.

1. Availability or uptime (downtime: planned and unplanned, tool change, tool service, job change etc.)

2. Performance efficiency (actual vs. design capacity)

3. Rate of quality output (Defects and rework)

A - Availability of the machine:

Thus $\mathrm{OEE}=\mathrm{A} * \mathrm{PE} * \mathrm{Q}$

Availability $=($ Planned production time - unscheduled downtime $)$

Planned production time

Production time $=$ Planned production time - Downtime 


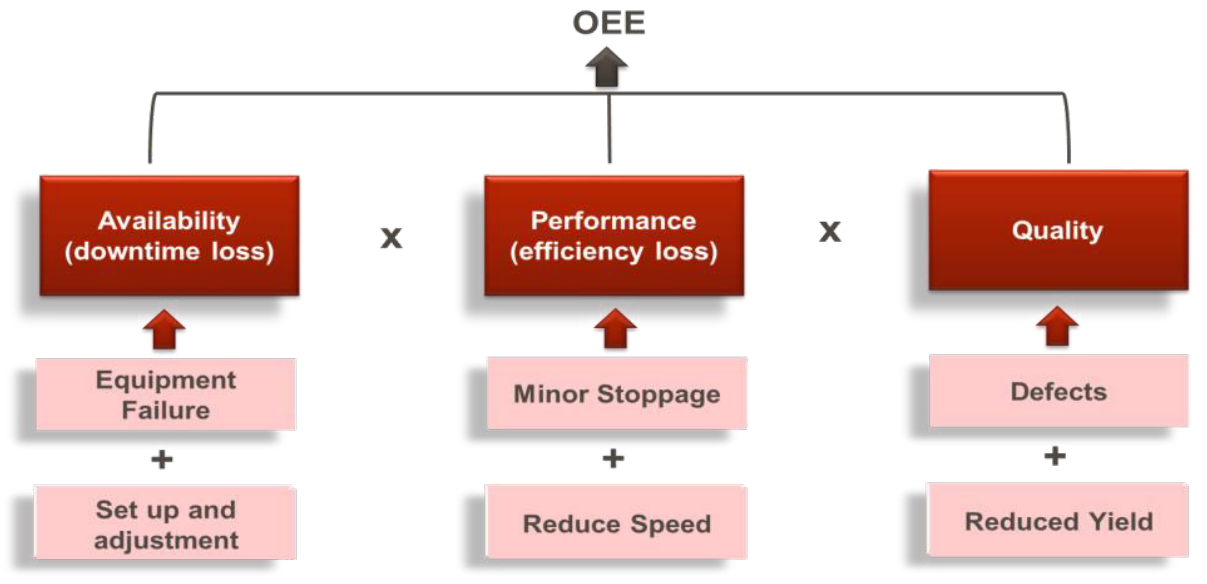

Fig. 1. Overall Equipment Efficiency methodology

\section{Observation on electric energy consumption in a hotel}

The electricity consumption details of 1 month collected from hotel management. In order to check the day to day variation in energy consumption, $\ddot{X}$ and $\mathrm{R}$ chart were plotted using Minitab 17 software. The below tables represents Energy consumptions recorded (table 2) for the month of OCTOBER- Before optimization of electricity units.

Table 2. Electrical Units Consumed/day

\begin{tabular}{|c|c|}
\hline Date & Units consumed/day \\
\hline $01 / 10 / 2016$ & 650 \\
\hline $02 / 10 / 2016$ & 732 \\
\hline $03 / 10 / 2016$ & 450 \\
\hline $04 / 10 / 2016$ & 385 \\
\hline $05 / 10 / 2016$ & 700 \\
\hline $06 / 10 / 2016$ & 714 \\
\hline $07 / 10 / 2016$ & 692 \\
\hline $08 / 10 / 2016$ & 701 \\
\hline $09 / 10 / 2016$ & 809 \\
\hline $10 / 10 / 2016$ & 980 \\
\hline $11 / 10 / 2016$ & 997 \\
\hline $12 / 10 / 2016$ & 1176 \\
\hline $13 / 10 / 2016$ & 1070 \\
\hline $14 / 10 / 2016$ & 962 \\
\hline $15 / 10 / 2016$ & 876 \\
\hline $16 / 10 / 2016$ & 456 \\
\hline $17 / 10 / 2016$ & 750 \\
\hline $18 / 10 / 2016$ & 369 \\
\hline $19 / 10 / 2016$ & 358 \\
\hline $20 / 10 / 2016$ & 655 \\
\hline $21 / 10 / 2016$ & 700 \\
\hline $22 / 10 / 2016$ & 458 \\
\hline $23 / 10 / 2016$ & 378 \\
\hline $24 / 10 / 2016$ & 678 \\
\hline
\end{tabular}




\begin{tabular}{|c|c|}
\hline $25 / 10 / 2016$ & 458 \\
\hline $26 / 10 / 2016$ & 687 \\
\hline $27 / 10 / 2016$ & 824 \\
\hline $28 / 10 / 2016$ & 925 \\
\hline $29 / 10 / 2016$ & 425 \\
\hline $30 / 10 / 2016$ & 714 \\
\hline $31 / 10 / 2016$ & 757 \\
\hline & Total units $=\mathbf{2 1 4 8 6}$ \\
\hline
\end{tabular}

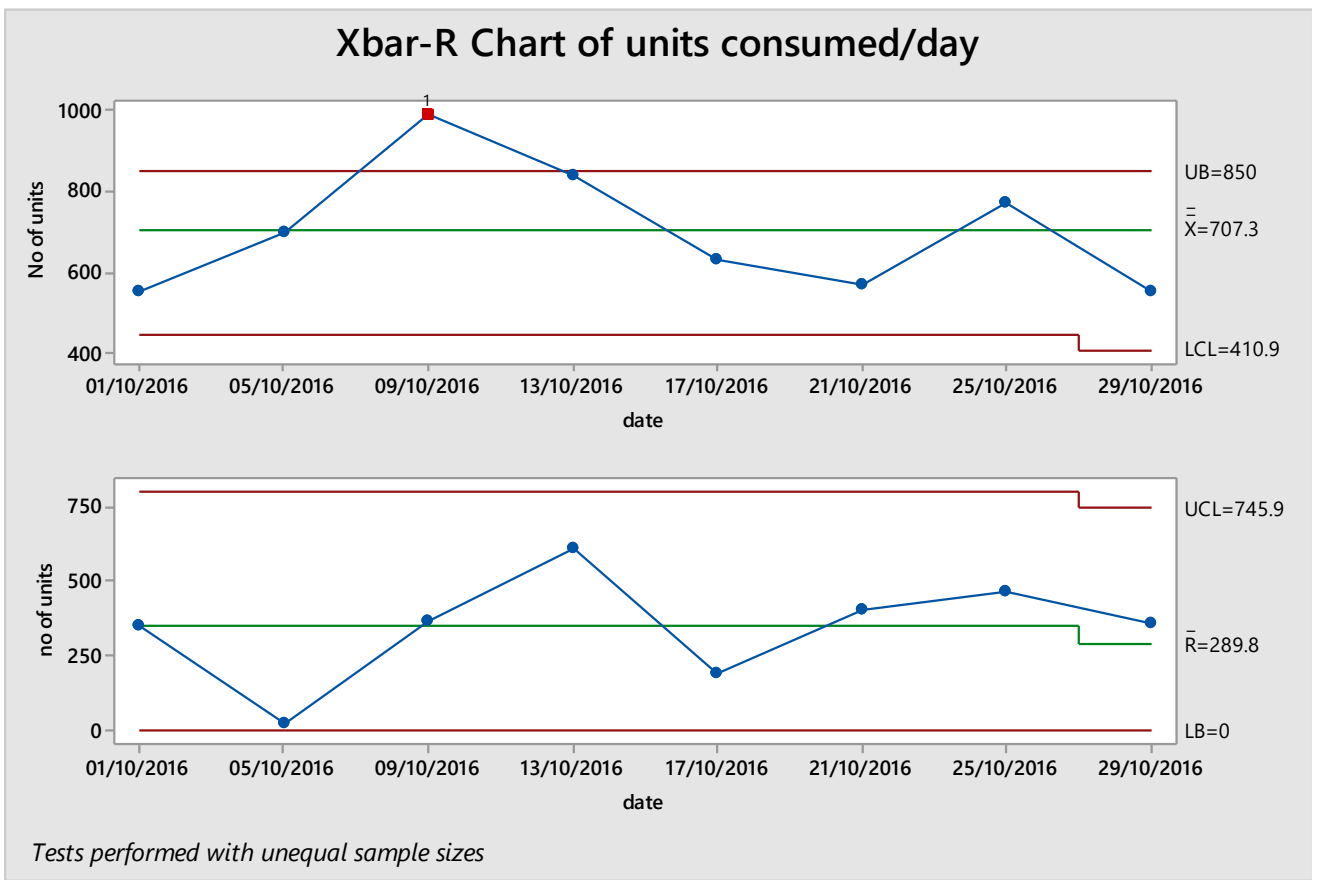

Fig. 2. Xbar and R-charts for Electricity consumed in October (in units)

The above graph represents Xbar-R Chart of electricity consumed during the month of October and it shows that consumption of electricity is not under control

\section{Implementation of tpm tool called focused improvement \& planned maintenance}

In simple words Focused improvement can be defined as a method that identifies the systems problems and then modifies the whole system in order to find the most cost effective, time saving and least disruptive solutions in order to optimize the system[6, 7]. Planned maintenance is another tool where an object, item, or equipment are maintained in a planned manner to increase the efficiency by reducing the downtime.

By adopting above methodologies the following suggestions were given.

1. Replaced incandescent bulbs with LED lights.

2. Introduced Fluorescent Ceiling Lights

3. Replaced the fixtures

4. Installed lower wattage or more efficient lamps 
Table 3 shows the differences between different bulbs to different parameters.

Table 3. LED Lights vs. Incandescent Bulbs vs. CFL bulbs

\begin{tabular}{|c|c|c|c|}
\hline & LED BULBS & CFL BULBS & $\begin{array}{l}\text { INCANDESCENT } \\
\text { BULBS }\end{array}$ \\
\hline Life Span (average) & $\begin{array}{l}50,000 \text { hours } \\
\text { Approximately, } \\
12 \text { years at } 10 \mathrm{hr} / \text { day } \\
20 \text { years at } 6 \mathrm{hr} / \text { day }\end{array}$ & $\begin{array}{l}1,200 \text { hours } \\
\text { Approximately, } \\
4 \text { month at } \\
10 \mathrm{hr} / \text { day } \\
6 \mathrm{month} \text { at } 6 \mathrm{hr} / \text { day }\end{array}$ & $\begin{array}{l}8,000 \text { hours } \\
\text { Approximately, } \\
2.2 \text { years at } 10 \mathrm{hr} / \text { day } \\
3.5 \text { years at } 6 \mathrm{hr} / \text { day }\end{array}$ \\
\hline $\begin{array}{l}\text { Watts of electricity } \\
\text { used } \\
\text { (equivalent to } 60 \\
\text { watt bulb). }\end{array}$ & $6-8$ watts & 60 watts & $13-15$ watts \\
\hline $\begin{array}{ll}\text { Kilo-watts } & \text { of } \\
\text { Electricity used }\end{array}$ & $\begin{array}{l}32 \mathrm{KWh} / \mathrm{yr} . \\
\text { Or } \\
32 \text { Units per year }\end{array}$ & $\begin{array}{l}320 \mathrm{KWh} / \mathrm{yr} . \\
\text { Or } \\
320 \text { Units per year }\end{array}$ & $\begin{array}{l}55 \mathrm{KWh} / \mathrm{yr} . \\
\text { Or } \\
55 \text { Units per year. }\end{array}$ \\
\hline $\begin{array}{l}\text { Annual Operating } \\
\text { Cost }\end{array}$ & Rs. 249.6/yr & Rs.2496/yr & $\mathrm{Rs} .429 / \mathrm{yr}$ \\
\hline
\end{tabular}

LEDs use less power (watts) per unit of light generated (lumens). LED has the Cheapest Operating Cost and Highest Life Span.

Calculations: at Avg. Electricity cost Rs7.80 per unit, at usage of $10 \mathrm{hr}$ per day per year Frequent maintenance and check-ups of the devices in Hotel were carried out as part of planned maintenance. PM avoids the break-down and maintains the efficiency, productivity, energy consumption of the process. After implementation of the above said suggestions to optimize the energy savings, the data were recorded as showed in Table 4.

November-After implementation of the above suggestions

Table 4. Units consumed/day after implementation

\begin{tabular}{|c|c|}
\hline Date & Units consumed/day \\
\hline $01 / 11 / 2016$ & 638 \\
\hline $02 / 11 / 2016$ & 720 \\
\hline $03 / 11 / 2016$ & 440 \\
\hline $04 / 11 / 2016$ & 360 \\
\hline $05 / 11 / 2016$ & 687 \\
\hline $06 / 11 / 2016$ & 704 \\
\hline $07 / 11 / 2016$ & 685 \\
\hline $08 / 11 / 2016$ & 689 \\
\hline $09 / 11 / 2016$ & 796 \\
\hline $10 / 11 / 2016$ & 969 \\
\hline $11 / 11 / 2016$ & 981 \\
\hline $12 / 11 / 2016$ & 964 \\
\hline $13 / 11 / 2016$ & 990 \\
\hline $14 / 11 / 2016$ & 941 \\
\hline $15 / 11 / 2016$ & 861 \\
\hline $16 / 11 / 2016$ & 439 \\
\hline
\end{tabular}




\begin{tabular}{|c|c|}
\hline $17 / 11 / 2016$ & 728 \\
\hline $18 / 11 / 2016$ & 355 \\
\hline $19 / 11 / 2016$ & 347 \\
\hline $20 / 11 / 2016$ & 640 \\
\hline $21 / 11 / 2016$ & 687 \\
\hline $22 / 11 / 2016$ & 441 \\
\hline $23 / 11 / 2016$ & 365 \\
\hline $24 / 11 / 2016$ & 664 \\
\hline $25 / 11 / 2016$ & 431 \\
\hline $26 / 11 / 2016$ & 675 \\
\hline $27 / 11 / 2016$ & 815 \\
\hline $28 / 11 / 2016$ & 913 \\
\hline $29 / 11 / 2016$ & 421 \\
\hline $30 / 11 / 2016$ & 704 \\
\hline $01 / 12 / 2016$ & 700 \\
\hline & Total units $=\mathbf{2 0 7 5 0}$ \\
\hline
\end{tabular}

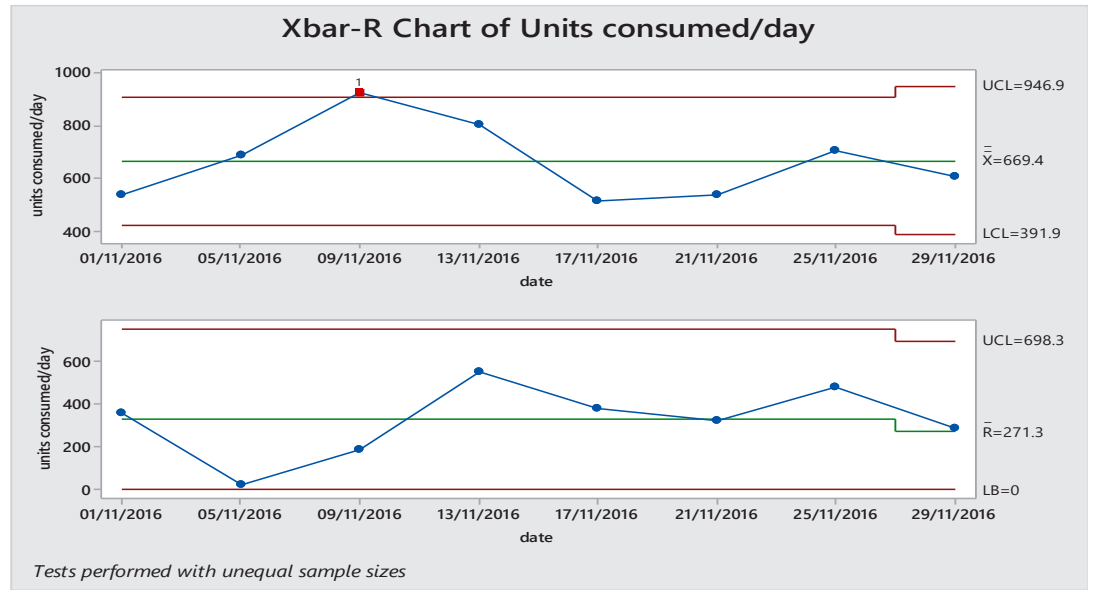

Fig. 3. Xbar and R-charts for Electricity consumed in November (in units)

\section{Results and discussions}

Figure 3 shows that consumption of electrical units in November are under control. After implementing the suggestions that are stated above, there was significant reduction in power consumption.

Cost reduction in terms of units of electricity saved is calculated:

Total No of units consumed in the month of October 2106 before TPM implementation $=21486$ (a)

Total No of units consumed in the month of November 2106 before TPM implementation= 20750(b)

Reduction in power consumption in units $=736$ units

Formula: Reduction of power consumption in $\%=\left(\frac{a-b}{a}\right) * 100$

$$
\begin{aligned}
& =\left(\frac{21486-20750}{21486}\right) \\
& =3.425 \%
\end{aligned}
$$

Price/unit of electricity $=$ Rs 7.80 
No. of units saved $=736$

Total cost reduction/month $=$ Rs 5740

Total cost reduction/year $=$ Rs 68889

The data shows only the one month energy or power consumption record, just by implementing small changes in the system. This small changes implementation has showed a significant improvement and increased profit in the system. The initial investment looks like a burden to the hotel management, but the outcome showed the profit to the Hotel industries. Many areas or departments are needed to be checked at the same time optimization can be achieved by TPM tools.

\section{Conclusions}

It has been observed that cost reduction and increasing energy efficiency were the two major necessities in the hotel operations. Just by replacing all incandescent bulbs with LED bulbs and using energy star qualified appliances can save up to $3.4 \%$ of total cost electricity per month. Result also showed the significant saving in terms of cost. Nowadays, for cost reduction and eliminating wastes it is very essential to go for industrial maintenance tools, techniques and alternative source of energy. It is also got to know that many areas are untouched for optimization in hotel departments. There is lot of need and scope to use the engineering tools to eliminate the issues facing in hotel industries.

\section{References}

1. Chan, K.T., Lee, R.H.K., \& Burnett, J. (2001). "Maintenance performance: a case study of hospitality engineering systems", Facilities, 19 (13/14) $494-504$

2. Chan, K. T., Lee, R.H.K., Burnett, J. (2003). "Maintenance Practices and Energy Performance of Hotel Buildings", Strategic Planning for Energy and the Environment, 23(1) 6-28.

3. Espino-Rodr'1guez, T., Padr'on-Robaina, V. (2005). "A resource-based view of outsourcing and its implications for organizational performance in the hotel sector" Tourism Management 26 (5), 707-721

4. Forsgren, S., Franchetti, C. (2004). "The marketing role of unique concepts for hotels in Sweden" Tourism and Hospitality Management Master Thesis No. 2004: 53, Goteborg University

5. Guilding, C. (2003). "Hotel owner/operator structures: implications for capital budgeting process", Management Accounting Research, 14(3) 179-199.

6. Hassanien, A., \&Losekoot, E. (2002). "The application of facilities management expertise to the hotel renovation process", Facilities, 20 (7/8), $230-238$

7. Jordhus-Lier, D., Bergene, A. C., Knutsen, H. M., \&Underthun, A. (April 2012). "Hotel workplaces in Oslo and Akershus" Norwegian Institute for Urban and Regional Research, working paper 2012: 106 